\title{
Accelerometer-measured physical activity is not associated with 2 year weight change in African-origin adults from 5 diverse populations
}

Lara R. Dugas ${ }^{\text {Corresp.. }}{ }^{1}$ ， Stephanie Kliethermes ${ }^{2}$ ， Jacob Plange-Rhule ${ }^{3}$ ， Liping Tong ${ }^{1}$, Pascal Bovet ${ }^{4,5}$, Terrence E. Forrester ${ }^{6}$, Estelle V. Lambert ${ }^{7}$, Dale A. Schoeller ${ }^{8}$, Ramon A. Durazo-Arvizu ${ }^{1}$, David A Shoham , Guichan Cao ${ }^{1}$, Soren Brage ${ }^{9}$, Ulf Ekelund ${ }^{9,10}$, Richard S. Cooper ${ }^{1}$, Amy Luke ${ }^{1}$

1 Public Health Sciences, Stritch School of Medicine, Loyola University Chicago, Maywood, IL, United States

2 Department of Orthopedics \& Rehabilitation, University of Wisconsin, Madison, Madison, WI, United States

3 Department of Physiology, Kwame Nkrumah University of Science and Technology, Kumasi, Ghana

4 Institute of Social \& Preventive Medicine,, Lausanne University Hospital, Lausanne, VD, Switzerland

5 Ministry of Health, Victoria, Republic of Seychelles

${ }^{6}$ Solutions for Developing Countries, University of West Indies, Mona, Kingston, Jamaica

7 Division of Exercise Science and Sports Medicine, Health Sciences, University of Cape Town, Cape Town, South Africa

8 Nutritional Sciences, University of Wisconsin, Madison, Madison, WI, United States

9 MRC Epidemiology Unit, University of Cambridge, Cambridge, United Kingdom

10 Department of Sport Medicine, Norwegion School of Sport Sciences, Oslo, Norway

Corresponding Author: Lara R. Dugas

Email address: Idugas@luc.edu

Background: Increasing population-levels of physical activity (PA) is a controversial strategy for managing the obesity epidemic, given the conflicting evidence for weight loss from PA alone per se. We measured PA and weight change in a 3 year prospective cohort study in young adults from 5 countries (Ghana, South Africa, Jamaica, Seychelles and USA). Methods: 1,944 men and women had baseline data, and at least 1 follow-up examination including measures of anthropometry (weight/BMI), and objective PA (accelerometer, 7day) following the 3 year study period. PA was explored as 1-minute bouts of moderate and vigorous PA (MVPA) as well as daily sedentary time. Results: At baseline; Ghanaian and South African men had the lowest body weights $(63.4 \pm 9.5,64.9 \pm 11.8 \mathrm{~kg}$, respectively) and men and women from the USA the highest $(93.6 \pm 25.9,91.7 \pm 23.4 \mathrm{~kg}$, respectively). Prevalence of normal weight ranged from $85 \%$ in Ghanaian men to $29 \%$ in USA men and $52 \%$ in Ghanaian women to $15 \%$ in USA women. Over the 2 year follow-up period, USA men and Jamaican women experienced the smallest yearly weight change rate $(0.1 \pm 3.3 \mathrm{~kg} / \mathrm{yr} ;-0.03 \pm 3.0 \mathrm{~kg} / \mathrm{yr}$, respectively), compared to South African men and Ghanaian women greatest yearly change $(0.6 .0 \pm 3.0 \mathrm{~kg} / \mathrm{yr} ; 1.22 \pm 2.6 \mathrm{~kg} / \mathrm{yr}$, respectively). Mean yearly weight gain tended to be larger among normal weight participants at baseline than overweight/obese at baseline. Neither baseline MVPA nor sedentary time were associated with weight gain. Using multiple linear regression, only baseline weight, age 
and gender were significantly associated with weight gain. Discussion: From our study it is not evident that higher volumes of PA alone are protective against future weight gain, and, by deduction our data suggest that other environmental factors, such as the food environment may have a more critical role. 
1 Accelerometer-measured physical activity is not associated with 2 year weight change in 2 African-origin adults from 5 diverse populations

3

4

5

6

\section{1}

Lara Dugas ${ }^{1}$, Stephanie Kliethermes ${ }^{2}$, Jacob Plange-Rhule ${ }^{3}$, Liping Tong ${ }^{1}$, Pascal Bovet ${ }^{4}, 5$, Terrence E. Forrester ${ }^{6}$, Estelle V. Lambert ${ }^{7}$, Dale A. Schoeller ${ }^{8}$, Ramon A. Durazo-Arvizu${ }^{1}$, David A. Shoham¹, Guichan Cao1, Soren Brage ${ }^{9}$, Ulf Ekelund ${ }^{9}, 10$, Richard S. Cooper $^{1}$, Amy Luke ${ }^{1}$

Running Head: MVPA and longitudinal weight gain

${ }^{1}$ Public Health Sciences, Stritch School of Medicine, Loyola University Chicago, Maywood, IL, USA

${ }^{2}$ Department of Orthopedics and Rehabilitation, University of Wisconsin, Madison, Madison, WI, USA

${ }^{3}$ Kwame Nkrumah University of Science and Technology, Kumasi, Ghana

${ }^{4}$ Institute of Social \& Preventive Medicine, Lausanne University Hospital, Lausanne, Switzerland 5 Ministry of Health, Victoria, Republic of Seychelles

${ }^{6}$ Soolutions for Developing Countries (SODECO), University of the West Indies, Mona, Kingston, Jamaica

${ }^{7}$ Division of Exercise Science and Sports Medicine, Department of Human Biology, Faculty of Health Sciences, University of Cape Town, Cape Town, South Africa

${ }^{8}$ Department of Nutritional Sciences, University of Wisconsin, Madison, Madison, WI, USA

${ }^{7}$ MRC Epidemiology Unit, University of Cambridge, Cambridge, UK

${ }^{8}$ Department of Sport Medicine, Norwegian School of Sport Sciences, Oslo, Norway

Corresponding author: Dr Lara R. Dugas, ldugas@luc.edu;

Phone: 708327 9029; Fax 7083279009 
33

34

35

36

37

38

39

40

41

42

43

44

45

46

47

48

49

50

51

52

53

54

55

56

57

\section{Abstract}

Background: Increasing population-levels of physical activity (PA) is a controversial strategy for managing the obesity epidemic, given the conflicting evidence for weight loss from PA alone per se. We measured PA and weight change in a 3 year prospective cohort study in young adults from 5 countries (Ghana, South Africa, Jamaica, Seychelles and USA).

Methods: 1,944 men and women had baseline data, and at least 1 follow-up examination including measures of anthropometry (weight/BMI), and objective PA (accelerometer, 7-day) following the 3 year study period. PA was explored as 1-minute bouts of moderate and vigorous PA (MVPA) as well as daily sedentary time.

Results: At baseline; Ghanaian and South African men had the lowest body weights $(63.4 \pm 9.5$, $64.9 \pm 11.8 \mathrm{~kg}$, respectively) and men and women from the USA the highest $(93.6 \pm 25.9,91.7 \pm 23.4$ $\mathrm{kg}$, respectively). Prevalence of normal weight ranged from $85 \%$ in Ghanaian men to $29 \%$ in USA men and $52 \%$ in Ghanaian women to $15 \%$ in USA women. Over the 2 year follow-up period, USA men and Jamaican women experienced the smallest yearly weight change rate $(0.1 \pm 3.3 \mathrm{~kg} / \mathrm{yr}$; $0.03 \pm 3.0 \mathrm{~kg} / \mathrm{yr}$, respectively), compared to South African men and Ghanaian women greatest yearly change $(0.6 .0 \pm 3.0 \mathrm{~kg} / \mathrm{yr} ; 1.22 \pm 2.6 \mathrm{~kg} / \mathrm{yr}$, respectively). Mean yearly weight gain tended to be larger among normal weight participants at baseline than overweight/obese at baseline. Neither baseline MVPA nor sedentary time were associated with weight gain. Using multiple linear regression, only baseline weight, age and gender were significantly associated with weight gain.

Discussion: From our study it is not evident that higher volumes of PA alone are protective against future weight gain, and, by deduction our data suggest that other environmental factors, such as the food environment may have a more critical role. 
58

59

60

61

62

63

64

65

66

67

68

69

70

71

72

73

74

75

76

77

78

79

80

81

82

83

\section{Introduction}

9

0

Increasing population-levels of physical activity (PA) is considered a strategy for managing

the obesity epidemic but this is controversial, with both sides of the debate providing strong arguments (Hill et al. 2015; Luke \& Cooper 2013). Many experts argue that a decline in PA, particularly from occupation-related activities, is a key contributor to the current obesity epidemic (Archer et al. 2013; Blair et al. 2013; Hill \& Peters 2013; Popkin 2001; Popkin et al. 2012; Popkin \& Gordon-Larsen 2004); however prospective longitudinal studies employing objective measures of PA have not identified a meaningful relationship between weight gain and PA (Dugas et al. 2014; Ebersole et al. 2008; Luke et al. 2014; Swinburn et al. 2009; Tataranni et al. 2003). The debate over the primary determinants of the worldwide obesity epidemic is more than simply academic; understanding obesity's etiology is critical for informing policy and allocating scarce public health funding.

Most studies examining the relationship between longitudinal weight gain and PA have relied on self-report measures, typically questionnaires (Paul et al. 2014; Song et al. 2014). The nature of many common PA questionnaires lend themselves to significant over-reporting of daily PA levels (Atienza et al. 2011; Belcher et al. 2014; Schuna et al. 2013; Tucker et al. 2011; Tucker et al. 2015), as participants are asked to report domain-based PA levels (i.e. transport, occupation and leisure time), and inaccuracy can also arise because some questionnaires often request participants to only report PA when they engage in PA during periods of at least 10-mins. Due to the social desirability of portraying oneself as engaging in healthy behaviors, e.g. being physically active, survey participants often report higher than actual levels of healthful behaviors (Klesges et al. 2004; Phillips \& Clancy 1972), and this bias may differ according to sex, socio-economic status and other characteristics. This over-statement of daily PA was illustrated by Tucker et al. (Tucker et al. 2011) using NHANES data, who found that $59.6 \%$ of USA adults reported that they met the USA Surgeon General guidelines (i.e., accumulated $150 \mathrm{~min} /$ week of moderate and 
84 vigorous activity), however, using objective activity monitoring data, overall only $8.2 \%$ of the same 85 USA adults met the recommended guidelines. This also demonstrates the need to rely on 86 objectively measured PA data to fully understand the role of PA in health.

87 The Modeling the Epidemiologic Transition Study (METS) is a prospective cohort study of 88 weight change in 2,500 young adults aged 25-45 years of predominantly African descent from 89 community-based samples in 5 countries at different levels of socio-economic development (Luke 90 et al. 2012; Luke et al. 2014). The countries span the UN Human Development Index (HDI), thus 91 representing a range of social and economic development, and include Ghana, South Africa, 92 Jamaica, Seychelles and the USA. Participants were examined in local study clinics every year, which provide yearly measures of participant characteristics, health behavior, and objectively measured PA. The purpose of this study was to objectively assess whether PA measured at baseline is associated with subsequent 2 year weight change in a cohort of diverse populations.

\section{Materials and Methods}

Sampling Design and Participant Recruitment:

Twenty-five hundred adults, ages 25-45, were enrolled in METS between January 2010 and

December 2011. After the baseline exam, participants were asked to return to the clinic yearly for an additional 2 clinic exams: 1 year follow-up and 2 year follow-up. Participants were excluded if they self-reported that they were either HIV positive or pregnant at the time of recruitment. During the follow-up period, if a participant was pregnant or lactating, they're weight data was not recorded during that year's follow-up visit, only the health history. Participants were also asked about voluntary weight loss and other recreational drug use. One person was excluded from the USA cohort for intentionally losing $36 \mathrm{~kg}$. For the current analysis, follow-up time varied between 1.32 years in Jamaican men to 1.98 years in Seychellois women (Table 1). Consequently, all analyses were adjusted for differing follow-up times and as described in the statistics section. A 
110 detailed description of the study protocol has been previously published (Luke et al. 2012). In

111 brief; participants, approximately $50 \%$ of whom were female, were enrolled in each of 5 study

112 sites: rural Ghana, urban South Africa, the Seychelles, urban Jamaica and metropolitan USA

113 (Chicago). The participants were predominantly of African descent from each of the five

114 countries. Study sites were selected to represent a broad range of social and economic

115 development as defined by the UN HDI 2011: i.e., Ghana as a low middle HDI country (HDI rank

116 135), South Africa as middle (123), Jamaica (80) and the Seychelles as high (52), and the US as

117 a very high HDI country (4).

118 METS was approved by the Institutional Review Board (IRB) of Loyola University Chicago, IL,

119 USA; the Committee on Human Research Publication and Ethics of Kwame Nkrumah University 120 of Science and Technology, Kumasi, Ghana; the Health Sciences Faculty Research Ethics 121 Committee of the University of Cape Town, South Africa; the Board for Ethics and Clinical 122 Research of the University of Lausanne, Switzerland; the Research Ethics Committee of the 123 Ministry of Health in Seychelles; the Ethics Committee of the University of the West Indies, 124 Kingston, Jamaica; and the Health Sciences IRB of the University of Wisconsin, Madison, WI, 125 USA. Written informed consent was obtained from all participants.

Measurements

Yearly measurements were made at outpatient clinics located in the respective communities. Weight and height measurements were made on all participants while wearing light clothing and no shoes and using the same model of equipment, which was calibrated using the

131 same protocol at each locale. Weight was measured to the nearest $0.1 \mathrm{~kg}$ using the same 132 standard balance at all five sites and during the entire study period (Seca 770, Hamburg, 133 Germany). Height was measured to the nearest $0.1 \mathrm{~cm}$ using a stadiometer (e.g. Invicta 134 Stadiometer, Invicta, London, UK). Waist circumference was measured to the nearest $0.1 \mathrm{~cm}$ at 
135 the umbilicus and hip at the point of maximum extension of the buttocks. Body mass index (BMI) 136 was calculated as $\mathrm{kg} / \mathrm{m}^{2}$.

137 Body composition was estimated by bioelectrical impedance analysis (BIA) with the use 138 of single-frequency (50 kHz) impedance analyzer (model BIA 101Q; RJL Systems, Clinton 139 Township, MI). Fat-free mass (FFM) and fat mass (FM) were estimated from measured 140 resistance by using an equation validated in the METS cohorts (Luke et al. 1997).

141 PA was assessed using Actical accelerometers (Phillips Respironics, Bend, OR, USA) as 142 previously described (Dugas et al. 2014; Luke et al. 2014). Briefly, the monitor was worn at the 143 waist, over an 8-day period encompassing the partial first and last days, including during sleep. 144 We assessed activity conducted between the hours of 7 am-11 pm daily. Raw data downloaded 145 from the accelerometers were first passed through a SAS macro program (2014) designed to infer 146 non-wear time from 90 or more minutes of continuous zero activity counts. A valid day of PA 147 monitoring was defined as one having 10 or more hours of wear time and participant files were 148 included if they contained $\geq 4$ or more valid days. Using the same protocol employed by the 149 National Center for Health Statistics for the analysis of accelerometry data in the continuous 150 National Health and Nutrition Examination Survey (Troiano et al. 2008), minutes defined as 151 comprising sedentary, moderate, vigorous or moderate plus vigorous activity are presented as 152 the total time in minutes ( $\mathrm{min}$ ) per day accumulated in either 1- or 10- min intervals and this was 153 averaged for the number of days with valid accelerometry data.

154

155 
156

157

158

159

160

161

162

163

164

165

166

167

168

169

170

171

172

173

174

175

176

177

178

179

180

181

Statistical Analysis

Data management was centralized at Loyola University Chicago. All data forms and questionnaires were scanned at each study site and, along with electronic Actical data files, were sent via secure FTP (Bitvise Tunnelier) to the data manager at the coordinating center.

Descriptive statistics were used to summarize the characteristics of participants in each of the five study sites, including descriptive characteristics of the physical activity variables. Because the yearly follow up periods were not identical in the different sites or within sites, all analyses on weight change were adjusted for the different follow-up periods. Univariate analyses were conducted to determine partial correlation coefficients between parameters of PA and 2 year weight change, after adjustment for age and follow up duration, and accounting for multiple observations for each individual (Hill et al. 2015). Partial correlation coefficients between weight change and PA are also presented separately among persons who gained weight and among persons who lost weight during follow up. For the purpose of our analysis, yearly weight change $(\mathrm{kg} / \mathrm{yr})$ was defined as the difference between the first and last recorded weight measure over the follow-up period, while weight loss and weight gain were defined simply by whether the final weight measurement either exceeded or was lower than the baseline starting weight (Table 2).

\section{Multilevel models}

Because the follow-up time was different between participants and sites, and some participants only had one follow-up measurement, we used the multi-level random slope and intercept model, which allowed us to use all available data points, to examine the associations between weight PA variables, including sedentary time. Briefly, for Level 1; an individual's weight (kg) from each examination was regressed on follow-up time. Secondly, level 2 models the potential dependence of the individual baseline weight (random intercept from level 1) and rate of weight change (kg/yr, random slope of level 1) as a function of the other covariates. The multilevel model is as follows: 
182

183

184

185

186

187

188

189

190

191

192

193

194

195

196

197

198

199

200

201

202

203

204

205

206

207
Level 1: Weight $_{i j}=\beta_{0 i}+\beta_{1 i} T_{i j}+\varepsilon_{i j}(1)$

Level 2: $\beta_{0 i}=\alpha_{0}+\alpha_{1}$ Base Weight $_{i}+\alpha_{2}$ Age $_{i}+\alpha_{3}$ Gender $_{i}+\alpha_{4}$ Site $_{i}+\alpha_{5}$ Physical Activity $_{i}+\xi_{0 i}(2)$

$\beta_{1 i}=\gamma_{0}+\gamma_{1}$ ghana $_{i}+\gamma_{2}$ rsa $_{i}+\gamma_{3}$ jamaica $_{i}+\gamma_{4}$ seychelles $_{i}+\gamma_{5}$ Physical Activity $_{i}+\xi_{1 i}(3)$,

where $i=1,2 \ldots \mathrm{N}$ and $j=1,2$. The effect of the PA variables on weight change is measured by the interaction coefficient $\gamma_{5}$, and the average effect of the PA variables on weight change estimate by $\alpha_{5}$. We have previously used this multi-level approach (Luke et al. 2009), which utilizes all available data, including incomplete data, and the within- and between-person variability, while adjusting for potential confounders such as age and baseline weight. All analyses were conducted using SAS (SAS Institute, Cary, NC USA, version 9.4) and a conventional 2-sided $5 \%$ alpha error was used to denote statistical significance.

\section{Results}

\section{Subject characteristics}

Baseline measures where completed in 2010 and 2011 and follow-up yearly exams during $2011 / 2012$ (follow-up 1) and 2012/2013 (follow-up 2). At baseline, a total of 2,506 participants were enrolled from the 5 sites over the enrollment period. Two thousand and sixty eight participants returned for a 1 year follow-up, Ghana $(n=417)$, South Africa $(n=414)$, Jamaica $(n=399)$, Seychelles $(n=481)$ and the USA $(n=357)$. While a total of 1,408 participants returned for a second follow-up visit, Ghana $(n=289)$, South Africa $(n=322)$, Jamaica $(n=136)$, Seychelles $(n=456)$ and finally, the USA $(n=205)$. The final sample therefore included a total of 888 men and 1,056 women with at least complete baseline measurements and 1 follow-up clinic visit (Table 1). We did exclude one participant from the USA intentionally lost $36 \mathrm{~kg}$ after the baseline visit.

The mean age among the men and women were $34.9 \pm 6.16 \mathrm{yr}$ and ranged from $33.7 \pm$ $5.6 \mathrm{yr}$ in the South African men to $36.6 \pm 5.1 \mathrm{yr}$ in the Seychellois men. Among men and women, 
208 mean time between the baseline visit and 2-year follow-up visit ranged from $1.32 \pm 0.46$ years 209 among the Jamaican men and $1.98 \pm 0.27$ years among the Seychellois women. As a result, all 210 of our statistical modeling was adjusted for both age and follow-up time differences.

211 The mean baseline weights were different among the 5 sites, with the lowest weights being 212 captured among men from Ghana and South Africa (63.4 \pm 9.5 and $64.9 \pm 11.8 \mathrm{~kg}$, respectively) 213 and highest among the USA men $(93.6 \pm 25.9 \mathrm{~kg})$. Among the women, Ghanaians weighed less 214 than USA women $(63.3 \pm 12.7$ vs. $91.7 \pm 23.4 \mathrm{~kg})$. Figures $1 \mathrm{a}$ and $1 \mathrm{~b}$ present the weight change 215 and PA data by site. After the 2 year follow-up period, surprisingly USA men experienced the 216 smallest yearly weight change $0.05 \pm 3.27 \mathrm{~kg} / \mathrm{yr}$, while among the women, the Jamaicans actually 217 lost on average $-0.03 \pm 2.79 \mathrm{~kg} / \mathrm{yr}$. In both men and women, yearly weight change was always 218 greater among participants categorized as normal weight $\left(\mathrm{BMl}<25 \mathrm{~kg} / \mathrm{m}^{2}\right)$ at baseline. For 219 example, normal weight men from Seychellois and Ghana experienced a yearly weight gain 220 between $0.56-0.58 \mathrm{~kg} / \mathrm{yr}$, respectively, compared to their obese counterparts who actually 221 experienced a yearly weight loss between $-0.28-2.06 \mathrm{~kg} / \mathrm{yr}$, respectively (Table 2). Similarly, 222 among the women, yearly weight gain was greatest among the normal and overweight 223 participants, than among the obese participants, ranging from $0.23 \pm 1.95 \mathrm{~kg} / \mathrm{yr}$ in the Jamaicans up to $1.37 \pm 2.53 \mathrm{~kg} / \mathrm{yr}$ among the Ghanaian women.

Table 3 presents the absolute weight change data across the entire follow-up period, by 226 site and sex, stratifying for either overall weight gain or weight loss. The number of men gaining weight (end weight>start weight) ranged from $40 \%$ among the Jamaicans to $54 \%$ among the Seychellois. The absolute weight gain varied from $3.2 \pm 2.4 \mathrm{~kg}$ to $4.5 \pm 3.5 \mathrm{~kg}$. Among the women, the number of participants gaining weight varied widely from $44 \%$ of the Jamaicans, who gained on average $3.1 \pm 1.9 \mathrm{~kg}$ up to $77 \%$ of the South African women, who gained $6.4 \pm 5.3 \mathrm{~kg}$.

Accelerometer PA at baseline, measured as either 10-min or 1-min bouts (Table 1), was 232 greatest among the South African men, who accumulated almost $1 \mathrm{hr} /$ day of MPVA in 1-min bouts and among the women, greatest in the Ghanaian women, who accumulated almost $30 \mathrm{~min} /$ day 
234 in 1-min MVPA bouts. Sedentary activity, also measured as either 10-min or 1-min bouts, was 235 greatest among the Jamaican men (266.9 $\pm 60.2 \mathrm{~min} /$ day in 1-min bouts) and highest among the 236 South African women (247.2 $\pm 44.7 \mathrm{~min} /$ day in 1 -min bouts).

237 We categorized participants at each site by whether they met the USA Surgeon General 238 guidelines for PA, i.e. 30 min/day on most days of the week, using the 1-min MVPA data. Among 239 the men, over $76 \%$ of Ghanaians $(\mathrm{N}=158)$ and South Africans $(\mathrm{N}=183)$ met the guidelines, 240 compared to only $44 \%$ of USA men $(\mathrm{N}=109)$. Far fewer women met this guideline, with only $44 \%$ 241 of Ghanaian women ( $N=130)$ compared to about $20 \%$ of USA women $(N=50)$.

242 Surprisingly, the total weight gain at every site, were actually greater among participants 243 who met the PA guidelines (Table 2) than among their site counterparts who did not meet the PA 244 guidelines. For example among USA men who met the PA guidelines, yearly weight change was $0.25 \pm 5.05 \mathrm{~kg} / \mathrm{y}$ compared to a loss of $0.29 \pm 4.09 \mathrm{~kg} / \mathrm{yr}$ among those not meeting the guideline Similarly, among the women, at each site, weight gain was less among the participants not meeting the PA guidelines, for example among South Africa women meeting the PA guidelines exception, where women meeting the guideline lost $0.4 \pm 5.1 \mathrm{~kg} / \mathrm{yr}$, compared to an average weight increase of $0.1 \pm 4.1 \mathrm{~kg} / \mathrm{yr}$ in those failing to meet the guideline.

At baseline, overweight Ghanaians and South Africans were $0.49(95 \% \mathrm{Cl}$ 0.32-0.75, $\mathrm{p}=0.001)$ and $0.48(95 \% \mathrm{Cl} 0.29-0.77, \mathrm{p}=0.003)$ times as likely to meet the PA guidelines at baseline compared to normal weight participants. Among the obese, Ghanaians, South Africans and USA participants were $71 \%, 78 \%$ and $62 \%$ less likely to meet the PA guidelines $(p<0.001$ for all) at baseline.

257 Relationship between weight change, and baseline physical activity and sedentary 258 behavior 
Tables 5a-c present the partial correlation coefficients between weight change and PA.

260 Because overall 10-min bout MVPA was so low, we chose to model our exploratory statistics 261 using 1-min bout MVPA only. We adjusted all analyses for age and length of follow-up and 262 restricted the analyses to each site to account for differences in site weight change.

263 Among the men, overall weight change did not correlate with 1-min bout MVPA at any of 264 the sites. Because this was not the expected relationship, we also performed this analysis on 265 only the participants who either gained or lost weight, but this also did not produce any statistically 266 significant associations. For example, among the participants who lost weight, only women from 267 the Seychelles had a significant relationship for 1-min bout MVPA and weight loss $(r=0.326$, $268 \mathrm{p}=0.015)$, while among participants who gained weight, the only significant relationship between 269 PA and weight gain was among the USA women who actually had a positive result $(r=0.218$, $270 p=0.026)$, indicating higher PA levels resulted in greater weight gain.

271 Sedentary behavior, in recent years, has been thought to be a key component contributing 272 to an increased risk for overall morbidity and mortality, independent of daily PA. Therefore, we 273 also examined the relationship between sedentary time at baseline and prospective weight 274 change during the two year follow up period (Tables 5a-c). Weight change was negatively 275 associated with sedentary time at baseline, only among the Ghanaian women ( $r=-0.147$, $276 p=0.029)$, i.e. weight gain was less among those with greater sedentary time at baseline. We did 277 not find any significant relationships between either weight gain or weight loss and baseline 278 sedentary time among any of the sites (Figures $2 a$ and $2 b$ ). Furthermore, we found that the nature 279 of the relationship between the two variables was inconsistent, with some relationships being 280 positive, while others negative.

\section{Multi-level models}

283 Table 6 presents the parameter estimates for weight change using baseline MVPA (model 284 1), baseline light activity (model 2) and baseline sedentary activity (model 3), all based on 1-min 
285 bouts, and with analyses adjusted for follow up time and age. In model 1, it can be seen that 286 baseline MVPA is not significantly associated with prospective weight, only the interaction term 287 between follow-up time and the South African site, where each year of follow-up time is associated 288 with an increase in weight that is on average $0.96 \mathrm{~kg}$ greater than the USA $(p=0.02)$. This outcome 289 was similarly found for model 2 (light activity and model 3, sedentary activity. In addition, among 290 the 3 models; baseline weight, age and gender were all significantly associated with weight.

291

292

293

294

295

296

297

298

299

300

301

302

303

304

305

306

307

308

309

\section{Discussion}

The first finding is that body weight increased during the two year follow up period in both men and women, except among women in Jamaica. Second, there were significant differences in the 2 year weight change according to sex and country, with a trend towards larger weight gain in countries with lower HDI. Third, weight gain tended to be lower among the obese participants than the normal weight participants, in all sites and sexes, and fourth, PA at baseline was not associated with two year follow up weight change.

Previously we reported weight change data from a similar international study comparing adults residing in either the USA, Jamaica and Nigeria over a 4 year period between 1995-1999 (Durazo-Arvizu et al. 2008). Time-adjusted weight gain was highest among the Jamaicans (1.37 $\mathrm{kg} / \mathrm{yr})$, compared to USA $(0.52 \mathrm{~kg} / \mathrm{yr})$ and Nigerians $(0.31 \mathrm{~kg} / \mathrm{yr})$. Fifteen years ago Jamaica represented a country under-going rapid transition as a result of accelerating cultural and behavioral shifts. In our current data set, South Africa and Ghana represent countries undergoing more rapid transition, and again we find similar results, whereby countries undergoing more rapid transition, as reflected by their changing HDI, experience greater time-adjusted yearly weight gain rates. The yearly weight gain rates for Ghana and South Africa were: 1.41 and 1.54 $\mathrm{kg} / \mathrm{yr}$ respectively, compared to Jamaica, and the USA 0.05, and $0.09 \mathrm{~kg} / \mathrm{yr}$, respectively. The exception were the Seychelles, where the rate of weight change is $1.6 \mathrm{~kg} / \mathrm{yr}$. 
311 and sedentary time) at baseline and prospective weight gain. Likewise, within each site, we

312 surprisingly found that participants meeting PA guidelines at baseline, i.e. accumulating $\geq 30$

$313 \mathrm{~min} /$ day, experienced higher rates of yearly weight gain, compared to those not meeting PA

314 guidelines. This is comparable to other large prospective studies such as the European

315 Prospective Investigation into Cancer and Nutrition (EPIC, (Ekelund et al. 2011)) and the

316 Women's Health Study (Lee et al. 2010) and has several public health policy implications for the

317 obesity epidemic. Indeed, the achievement of higher volumes of daily PA continues to be

318 presented as a possible global solution and management tool for the epidemic (2010a; 2010b;

$3192012 a ; 2012 b ; 2012 c ; 2013 a ; 2013 b)$. From our study with 1,944 young adults, higher volumes

320 of PA at baseline were not protective against future weight gain, suggesting that other

environmental factors, such as the food environment, may have a more pivotal role in weight gain.

Recent evidence from the United States-based Coronary Artery Risk Development in Young

Adults (CARDIA) cohort (Richardson et al. 2015) using 20 years of BMI follow-up data, found

significant effects for neighborhood fast food restaurants, such that BMI increases were associated with a higher consumption of an obesogenic fast food-type diet. This was after controlling for effects of SES and PA (Richardson et al. 2015). Interestingly, PA among the young adults decreased from baseline to the first follow-up (7 years), but then remained stable during the subsequent 3 follow-up measurements (13 years), while BMI continued to increase. undisputed (Glenn et al. 2015; Lin et al. 2015; Long et al. 2015), but that its role in the prevention of population level weight gain may be overstated.

Notably, yearly weight change rate, within each site, appeared to be smallest among the

334 participants characterized as either overweight or obese at baseline, and in many instances 335 overweight or obese participants actually experienced a negative yearly weight change rate. 
336 Overweight and obese men had a negative yearly weight change rate $(-0.27 \mathrm{~kg} / \mathrm{yr}$ and $-0.16 \mathrm{~kg} / \mathrm{yr}$,

337 respectively). A similar trend were captured among the women, where normal weight participants

338 experienced greater yearly weight change rates, compared to their overweight and obese 339 counterparts (Table 3).

340 Our data add to a growing body of literature reporting similar findings (Ekelund et al. 2011;

341 Lee et al. 2010; Luke et al. 2014; Luke et al. 2009; Luke et al. 2006; Moholdt et al. 2014; Pontzer

342 et al. 2012). Among participants in the EPIC study, baseline PA was not associated with

343 prospective weight gain (Ekelund et al. 2011). Further, there were differences between younger

$344(<50 \mathrm{yr})$ and older normal weight adults ( $\geq 50 \mathrm{yr})$ in the relationship between baseline PA and

345 prospective weight gain (Ekelund et al. 2011). Lee et al. (Lee et al. 2010) similarly found in 34,079

346 women (54.2 yr) no difference in weight gain $(2.6 \mathrm{~kg})$ comparing participants either meeting or

347 not meeting the USA PA guidelines ( $\geq 150 \mathrm{~min} /$ week moderate PA), only in those meeting higher

348 volume IOM PA guidelines ( $\geq 420 \mathrm{~min} /$ week moderate PA) over a period of 13 years. The

349 measurement periods were separated into 4 measurement periods and examining changes in PA

350

351

352

353

354

355

356

357

358

359

360

361

during the measurement period did also not result in differences in weight gain between the groups meeting or not meeting USA PA guidelines. Reported weight gain differences were only found among normal weight women $\left(\mathrm{BMl}<25 \mathrm{~kg} / \mathrm{m}^{2}\right)$ at baseline, who met the higher volume IOM PA guidelines, gaining less than $2.3 \mathrm{~kg}$ over the 13 year measurement period.

An important consideration is the direction of the PA-weight change relationship, i.e. does low PA contribute to greater future weight gain or does weight gain lead to future low PA levels? Golubic et al. (Golubic et al. 2013) found the second option to be true, namely weight gain is causal for low PA. Compared to participants who remained weight stable after 10 years of followup, those participants gaining between $0.5-2 \mathrm{~kg}$ were 1.26 times as likely to be inactive and almost twice as likely to be inactive if they gained more than $2 \mathrm{~kg}$. While we do not present the longitudinal PA outcomes in this paper, we did explore the cross-sectional associations between meeting USA PA guidelines and BMI at baseline. Ghanaians, South Africans and Americans 
362 were significantly less likely to meet the PA guidelines if they were either overweight or obese.

363 For example, obese Americans were $62 \%$ as likely to meet PA guidelines compared to normal 364 weight Americans. While we cannot show any causality using a cross-sectional analysis, future 365 investigations exploring the direction of the PA-weight gain relationship is a critical piece of this 366 international debate, with significant public health implications. If weight gain or being 367 overweight/obese precedes low PA levels, the public health message should reflect this.

368 We cannot ignore the wide ranging methodologies employed in studies exploring the 369 relationship between PA and weight gain, or vice versa. Methodological and/or instrumentation 370 differences are important factors in trying to compare the large body of evidence examining the 371 relationship between weight gain and PA levels. Whereas data from studies such as ours 372 employing objectively measured PA tend to show little or no correlation between PA and weight 373 change, studies using self-report tend to show an association between PA and weight gain (Paul 374 et al. 2014; Song et al. 2014). Self-report data may in fact express social desirability and be 375 biased toward healthy behaviors, which may ultimately be associated with smaller weight gain. Some studies investigating the association between PA and eating behavior find that self-report 377 PA is associated with increased eating self-regulation (Andrade et al. 2010; Martins et al. 2008). Assessment of PA based on self-report is highly variable in different studies reflecting a number of problems with measurement of self-reported PA. A recent study comparing self-report data in USA adults participating in 3 surveillance systems (NHIS, NHANES and BRFSS) found considerable variation among the self-report PA variables, ranging from population PA levels of $30 \%$ (NHIS) up to $48 \%$ in BRFSS (Carlson et al. 2009). Tucker et al (Tucker et al. 2011), found that USA adults may over report their PA by as much as $50 \%$, with $>60 \%$ of USA adults report that they meet the USA surgeon general guidelines ( $\geq 150 \mathrm{~min} /$ week of MVPA), however using objective activity monitoring data, only $8 \%$ actually meet the same PA guidelines. 
388 in which they reside and as such caution should be taken when interpreting the results across the 389 human development spectrum. Secondly, as a result of the ongoing nature of this study, 390 measurements were completed at different times of the calendar year/seasons at the 5 different 391 sites. However, in order to reduce measurement errors, we provided the same brand/model of 392 calibrated equipment items to all the research sites, and ensured their proper working order at all 393 times. We also feel confident in the robustness of our data as a result of exploring potential 394 seasonal/country differences and have found none to date (Sani et al. 2015) .

395

396 


\section{Conclusion:}

In conclusion, in this prospective cohort study in young adults from 5 countries, representing different stages of epidemiologic transition, baseline PA was not associated with weight change patterns were different and could not simply be accounted for by level of development, using a UN indicator. By deduction; our data suggest that other environmental factors that influence food consumption may be a more fertile field for public research and health 404 intervention.

\section{Acknowledgements}

The authors would like to acknowledge the site-specific clinic staff members as well as the 407 2,500 participants. LD, JPR, PB, TEF, EVL, DAS, RADA, DAS, SB, UE RC and AL all conceived 408 the idea for the manuscript, contributed to the data collection and analysis. SK, LP, and GC 409 performed further statistical analyses. All authors contributed equally to the drafting on the 410 manuscript. No authors declare a conflict of interest or any competing interests.

411

412 
414

415

416

417

418

419

420

421

422

423

424

425

426

427

428

429

430

431

432

433

434

435

436

437

438

439

440

441

442

443

444

445

446

447

448

449

450

451

452

453

454

455

456

457

458

459

460

461

462

463

\section{References}

Bitvise Tunnelier, Version 4.40. Available at http://www.bitvise.com/tunnelier (accessed 30 March 2011).

2010a. Global recommendations on physical activity for health. The World Health Organization. Geneva, Switzerland.

2010b. The Surgeon General's Vision for a Healthy and Fit Nation 2010. U.S. Department of Health and Human Services. Available at http://www.surgeongeneral.gov/initiatives/healthy-fit-nation/obesityvision2010.pdf (accessed May 6 2013).

2012a. Healthy People 2020. Available at http://www.healthypeople.gov/2020/.

2012b. Healthy People 2020. Leading Health Indicators. Available at http://www.healthypeople.gov/2020/LHI/default.aspx (accessed December 6 2012).

2012c. National Physical Activity Plan.

2013a. Global Physical Activity Surveliance. The World Health Organization. Available at http://www.who.int/chp/steps/GPAQ EN.pdf2013).

2013b. Physical Activity is Important to Good Health. U.S. Department of Health and Human Services. Available at http://healthfinder.gov/HealthTopics/Category/health-conditionsand-diseases/diabetes/get-active.

2014. SAS Programs for Analyzing NHANES 2003-2004 Accelerometer Data. Available at http://appliedresearch.cancer.gov/nhanes pam/ (accessed June 18 2012).

Andrade AM, Coutinho SR, Silva MN, Mata J, Vieira PN, Minderico CS, Melanson KJ, Baptista F, Sardinha LB, and Teixeira PJ. 2010. The effect of physical activity on weight loss is mediated by eating self-regulation. Patient education and counseling 79:320-326. 10.1016/j.pec.2010.01.006

Archer E, Shook RP, Thomas DM, Church TS, Katzmarzyk PT, Hebert JR, Mclver KL, Hand GA, Lavie CJ, and Blair SN. 2013. 45-Year trends in women's use of time and household management energy expenditure. PLoS One 8:e56620. 10.1371/journal.pone.0056620 PONE-D-12-28855 [pii]

Atienza AA, Moser RP, Perna F, Dodd K, Ballard-Barbash R, Troiano RP, and Berrigan D. 2011. Self-reported and objectively measured activity related to biomarkers using NHANES. Medicine and science in sports and exercise 43:815-821. 10.1249/MSS.0b013e3181fdfc32

Belcher BR, Moser RP, Dodd KW, Atienza AA, Ballard-Barbash R, and Berrigan D. 2014. SelfReported Versus Accelerometer-Measured Physical Activity and Biomarkers Among NHANES Youth. Journal of physical activity \& health. 10.1123/jpah.2013-0193

Blair SN, Archer E, and Hand GA. 2013. Commentary: Luke and Cooper are wrong: physical activity has a crucial role in weight management and determinants of obesity. International journal of epidemiology 42:1836-1838. 10.1093/ije/dyt160

Carlson SA, Densmore D, Fulton JE, Yore MM, and Kohl HW, 3rd. 2009. Differences in physical activity prevalence and trends from 3 U.S. surveillance systems: NHIS, NHANES, and BRFSS. Journal of physical activity \& health 6 Suppl 1:S18-27.

Dugas LR, Bovet P, Forrester TE, Lambert EV, Plange-Rhule J, Durazo-Arvizu RA, Shoham D, Kroff J, Cao G, Cooper RS, Brage S, Ekelund U, and Luke A. 2014. Comparisons of intensity-duration patterns of physical activity in the US, Jamaica and 3 African countries. BMC Public Health 14:882. 10.1186/1471-2458-14-882

Durazo-Arvizu RA, Luke A, Cooper RS, Cao G, Dugas L, Adeyemo A, Boyne M, and Forrester T. 2008. Rapid increases in obesity in Jamaica, compared to Nigeria and the United States. BMC Public Health 8:133. 1471-2458-8-133 [pii]

10.1186/1471-2458-8-133 
464

465

466

467

468

469

470

471

472

473

474

475

476

477

478

479

480

481

482

483

484

485

486

487

488

489

490

491

492

493

494

495

496

497

498

499

500

501

502

503

504

505

506

507

508

509

510

511

512

513

514

Ebersole KE, Dugas LR, Durazo-Arvizut RA, Adeyemo AA, Tayo BO, Omotade OO, Brieger WR, Schoeller DA, Cooper RS, and Luke AH. 2008. Energy expenditure and adiposity in Nigerian and African-American women. Obesity (Silver Spring) 16:2148-2154. oby2008330 [pii] 10.1038/oby.2008.330

Ekelund U, Besson H, Luan J, May AM, Sharp SJ, Brage S, Travier N, Agudo A, Slimani N, Rinaldi S, Jenab M, Norat T, Mouw T, Rohrmann S, Kaaks R, Bergmann MM, Boeing H, Clavel-Chapelon F, Boutron-Ruault MC, Overvad K, Jakobsen MU, Johnsen NF, Halkjaer J, Gonzalez CA, Rodriguez L, Sanchez MJ, Arriola L, Barricarte A, Navarro C, Key TJ, Spencer EA, Orfanos P, Naska A, Trichopoulou A, Manjer J, Lund E, Palli D, Pala V, Vineis P, Mattiello A, Tumino R, Bueno-de-Mesquita HB, van den Berg SW, Odysseos AD, Riboli E, Wareham NJ, and Peeters PH. 2011. Physical activity and gain in abdominal adiposity and body weight: prospective cohort study in 288,498 men and women. The American journal of clinical nutrition 93:826-835. 10.3945/ajcn.110.006593

Glenn KR, Slaughter JC, Fowke JH, Buchowski MS, Matthews CE, Signorello LB, Blot WJ, and Lipworth L. 2015. Physical activity, sedentary behavior and all-cause mortality among blacks and whites with diabetes. Annals of epidemiology.

10.1016/j.annepidem.2015.04.006

Golubic R, Ekelund U, Wijndaele K, Luben R, Khaw KT, Wareham NJ, and Brage S. 2013. Rate of weight gain predicts change in physical activity levels: a longitudinal analysis of the EPIC-Norfolk cohort. International journal of obesity 37:404-409. 10.1038/ijo.2012.58

Hill JO, and Peters JC. 2013. Commentary: physical activity and weight control. International journal of epidemiology 42:1840-1842. 10.1093/ije/dyt161

Hill JO, Peters JC, and Blair SN. 2015. Reducing obesity will require involvement of all sectors of society. Obesity 23:255. 10.1002/oby.20965

Klesges LM, Baranowski T, Beech B, Cullen K, Murray DM, Rochon J, and Pratt C. 2004. Social desirability bias in self-reported dietary, physical activity and weight concerns measures in 8- to 10-year-old African-American girls: results from the Girls Health Enrichment Multisite Studies (GEMS). Preventive medicine 38 Suppl:S78-87. 10.1016/j.ypmed.2003.07.003

Lee IM, Djousse L, Sesso HD, Wang L, and Buring JE. 2010. Physical activity and weight gain prevention. JAMA 303:1173-1179. 10.1001/jama.2010.312

Lin X, Zhang X, Guo J, Roberts CK, McKenzie S, Wu WC, Liu S, and Song Y. 2015. Effects of Exercise Training on Cardiorespiratory Fitness and Biomarkers of Cardiometabolic Health: A Systematic Review and Meta-Analysis of Randomized Controlled Trials. Journal of the American Heart Association 4. 10.1161/JAHA.115.002014

Long G, Watkinson C, Brage S, Morris J, Tuxworth B, Fentem P, Griffin S, Simmons R, and Wareham N. 2015. Mortality benefits of population-wide adherence to national physical activity guidelines: a prospective cohort study. European journal of epidemiology 30:7179. 10.1007/s10654-014-9965-5

Luke A, Bovet P, Forrester TE, Lambert EV, Plange-Rhule J, Schoeller DA, Dugas LR, DurazoArvizu RA, Shoham D, Cooper RS, Brage S, Ekelund U, and Steyn NP. 2012. Protocol for the modeling the epidemiologic transition study: a longitudinal observational study of energy balance and change in body weight, diabetes and cardiovascular disease risk. BMC Public Health 11:927. 1471-2458-11-927 [pii] 10.1186/1471-2458-11-927

Luke A, Bovet P, Plange-Rhule J, Forrester TE, Lambert EV, Schoeller DA, Dugas LR, DurazoArvizu RA, Shoham DA, Cao G, Brage S, Ekelund U, and Cooper RS. 2014. A mixed ecologic-cohort comparison of physical activity \& weight among young adults from five populations of African origin. BMC Public Health 14:397. 10.1186/1471-2458-14-397

Luke A, and Cooper RS. 2013. Physical activity does not influence obesity risk: time to clarify the public health message. International journal of epidemiology 42:1831-1836. 10.1093/ije/dyt159 
515

516

517

518

519

520

521

522

523

524

525

526

527

528

529

530

531

532

533

534

535

536

537

538

539

540

541

542

543

544

545

546

547

548

549

550

551

552

553

554

555

556

557

558

559

560

561

562

563

Luke A, Dugas LR, Ebersole K, Durazo-Arvizu RA, Cao G, Schoeller DA, Adeyemo A, Brieger WR, and Cooper RS. 2009. Energy expenditure does not predict weight change in either Nigerian or African American women. Am J Clin Nutr 89:169-176. ajcn.2008.26630 [pii] 10.3945/ajcn.2008.26630

Luke A, Durazo-Arvizu R, Cao G, Adeyemo A, Tayo B, and Cooper R. 2006. Positive association between resting energy expenditure and weight gain in a lean adult population. Am J Clin Nutr 83:1076-1081.

Luke A, Durazo-Arvizu R, Rotimi C, Prewitt TE, Forrester T, Wilks R, Ogunbiyi OJ, Schoeller DA, McGee D, and Cooper RS. 1997. Relation between body mass index and body fat in black population samples from Nigeria, Jamaica, and the United States. Am J Epidemiol 145:620-628.

Martins C, Morgan L, and Truby H. 2008. A review of the effects of exercise on appetite regulation: an obesity perspective. International journal of obesity 32:1337-1347. 10.1038/ijo.2008.98

Moholdt T, Wisloff U, Lydersen S, and Nauman J. 2014. Current physical activity guidelines for health are insufficient to mitigate long-term weight gain: more data in the fitness versus fatness debate (The HUNT study, Norway). British journal of sports medicine 48:14891496. 10.1136/bjsports-2014-093416

Paul P, Carlson SA, Carroll DD, Berrigan D, and Fulton JE. 2014. Walking for Transportation and Leisure Among U.S. Adults - National Health Interview Survey 2010. Journal of physical activity \& health. 10.1123/jpah.2013-0519

Phillips DL, and Clancy KJ. 1972. Some Effects of "Social Desirability" in Survey Studies. American Journal of Sociology 77:921-940. 10.2307/2776929

Pontzer H, Raichlen DA, Wood BM, Mabulla AZ, Racette SB, and Marlowe FW. 2012. Huntergatherer energetics and human obesity. PLoS One 7:e40503. 10.1371/journal.pone.0040503 PONE-D-12-02382 [pii]

Popkin BM. 2001. The nutrition transition and obesity in the developing world. $J$ Nutr 131:871S8735 .

Popkin BM, Adair LS, and Ng SW. 2012. Global nutrition transition and the pandemic of obesity in developing countries. Nutrition reviews 70:3-21. 10.1111/j.1753-4887.2011.00456.x

Popkin BM, and Gordon-Larsen P. 2004. The nutrition transition: worldwide obesity dynamics and their determinants. Int J Obes Relat Metab Disord 28 Suppl 3:S2-9.

Richardson AS, Meyer KA, Howard AG, Boone-Heinonen J, Popkin BM, Evenson KR, Shikany JM, Lewis CE, and Gordon-Larsen P. 2015. Multiple pathways from the neighborhood food environment to increased body mass index through dietary behaviors: A structural equation-based analysis in the CARDIA study. Health Place 36:74-87. 10.1016/j.healthplace.2015.09.003

Sani M, Refinetti R, Jean-Louis G, Pandi-Perumal SR, Durazo-Arvizu RA, Dugas LR, Kafensztok R, Bovet P, Forrester TE, Lambert EV, Plange-Rhule J, and Luke A. 2015. Daily activity patterns of 2316 men and women from five countries differing in socioeconomic development. Chronobiology international 32:650-656. 10.3109/07420528.2015.1038559

Schuna JM, Jr., Johnson WD, and Tudor-Locke C. 2013. Adult self-reported and objectively monitored physical activity and sedentary behavior: NHANES 2005-2006. The international journal of behavioral nutrition and physical activity 10:126. 10.1186/14795868-10-126

Song M, Carroll DD, Lee SM, and Fulton JE. 2014. Physical Activities of U.S. High School Students, National Youth Physical Activity and Nutrition Survey, 2010. Journal of physical activity \& health. 10.1123/jpah.2014-0117 
564

565

566

567

568

569

570

571

572

573

574

575

576

577

578

579
Swinburn B, Sacks G, and Ravussin E. 2009. Increased food energy supply is more than sufficient to explain the US epidemic of obesity. Am J Clin Nutr 90:1453-1456. ajcn.2009.28595 [pii] 10.3945/ajcn.2009.28595

Tataranni PA, Harper IT, Snitker S, Del Parigi A, Vozarova B, Bunt J, Bogardus C, and Ravussin E. 2003. Body weight gain in free-living Pima Indians: effect of energy intake vs expenditure. Int J Obes Relat Metab Disord 27:1578-1583.

Troiano RP, Berrigan D, Dodd KW, Masse LC, Tilert T, and McDowell M. 2008. Physical activity in the United States measured by accelerometer. Med Sci Sports Exerc 40:181-188. 10.1249/mss.0b013e31815a51b3

Tucker JM, Welk GJ, and Beyler NK. 2011. Physical activity in U.S.: adults compliance with the Physical Activity Guidelines for Americans. American journal of preventive medicine 40:454-461. 10.1016/j.amepre.2010.12.016

Tucker JM, Welk GJ, Beyler NK, and Kim Y. 2015. Associations Between Physical Activity and Metabolic Syndrome: Comparison Between Self-Report and Accelerometry. American journal of health promotion : AJHP. 10.4278/ajhp.121127-QUAN-576 


\section{Table 1 (on next page)}

Participants' characteristics by site for men $(N=869)$ and women $(N=1,027)$ 


\begin{tabular}{|c|c|c|c|c|c|}
\hline & \multicolumn{5}{|c|}{ Men $(\mathrm{N}=\mathbf{8 8 8})$} \\
\hline & Ghana $(\mathrm{N}=180)$ & RSA $(\mathrm{N}=183)$ & Jamaica $(\mathrm{N}=198)$ & Seychelles $(\mathrm{N}=171)$ & $\begin{array}{c}\text { USA } \\
(\mathrm{N}=156)\end{array}$ \\
\hline Age (yr) & $35.66 \pm 6.43$ & $33.79 \pm 5.55$ & $34.13 \pm 5.98$ & $36.62 \pm 5.08$ & $35.95 \pm 6.40$ \\
\hline Baseline weight (kg) & $63.35 \pm 9.48$ & $64.89 \pm 11.79$ & $73.71 \pm 15.72$ & $80.29 \pm 16.21$ & $\begin{array}{c}93.16 \pm 25.2 \\
4\end{array}$ \\
\hline $\begin{array}{l}\text { Baseline normal weight } \\
\left(B M \mid<25 \mathrm{~kg} / \mathrm{m}^{2}\right)\end{array}$ & $82.69 \%$ & $79.78 \%$ & $67.22 \%$ & $41.92 \%$ & $28.65 \%$ \\
\hline Weight change (kg) & $0.69 \pm 3.15$ & $0.76 \pm 4.67$ & $0.20 \pm 3.90$ & $0.81 \pm 5.22$ & $0.11 \pm 5.99$ \\
\hline Time change (yr) & $1.70 \pm 0.48$ & $1.61 \pm 0.62$ & $1.32 \pm 0.46$ & $1.98 \pm 0.27$ & $1.54 \pm 0.54$ \\
\hline Weight change rate $(\mathrm{kg} / \mathrm{yr})$ & $0.48 \pm 2.16$ & $0.50 \pm 3.44$ & $0.21 \pm 3.31$ & $0.42 \pm 2.61$ & $-0.08 \pm 4.47$ \\
\hline MVPA (min/day $10-\min$ bout) & $24.68 \pm 18.74$ & $31.66 \pm 27.79$ & $12.95 \pm 16.62$ & $16.67 \pm 17.11$ & $\begin{array}{c}18.88 \pm 29.4 \\
5\end{array}$ \\
\hline MVPA (min/day 1-min bout) & $51.54 \pm 26.25$ & $56.26 \pm 34.46$ & $31.37 \pm 24.65$ & $36.34 \pm 24.43$ & $\begin{array}{c}33.45 \pm 34.2 \\
9\end{array}$ \\
\hline Light (min/day 10-min bout) & $144.20 \pm 81.07$ & $76.88 \pm 55.40$ & $106.00 \pm 65.00$ & $129.84 \pm 87.12$ & $\begin{array}{l}117.67 \pm 80 \\
00\end{array}$ \\
\hline Light (min/day 1-min bout) & $253.65 \pm 77.51$ & $189.11 \pm 69.33$ & $219.30 \pm 70.76$ & $232.11 \pm 77.97$ & $\begin{array}{l}235.69 \pm 82 \\
32\end{array}$ \\
\hline Sedentary (min/day 10-min bout) & $54.08 \pm 40.15$ & $52.00 \pm 32.99$ & $79.92 \pm 53.05$ & $68.82 \pm 51.13$ & $\begin{array}{c}56.66 \pm 36.4 \\
5\end{array}$ \\
\hline Sedentary (min/day 1 -min bout) & $228.97 \pm 47.56$ & $241.37 \pm 45.16$ & $267.01 \pm 59.89$ & $212.67 \pm 57.92$ & $\begin{array}{l}249.71 \pm 56 \\
15\end{array}$ \\
\hline \multirow[t]{3}{*}{ Meets US PA guidelines (Yes) } & $74.36 \%$ & $76.50 \%$ & $42.78 \%$ & $55.56 \%$ & $38.01 \%$ \\
\hline & \multicolumn{5}{|c|}{ Women $(\mathrm{N}=1,055)$} \\
\hline & Ghana (N=186) & SA (N=234) & Jamaica (N=215) & $\begin{array}{l}\text { Seychelles } \\
(N=197)\end{array}$ & USA ( $N=223)$ \\
\hline Age (yr) & $34.87 \pm 6.64$ & $33.05 \pm 5.98$ & $34.92 \pm 6.24$ & $35.78 \pm 6.02$ & $35.77 \pm 6.01$ \\
\hline Baseline weight (kg) & $63.28 \pm 12.67$ & $82.78 \pm 21.87$ & $80.04 \pm 19.16$ & $70.65 \pm 16.11$ & $\begin{array}{c}91.94 \pm 23.3 \\
5\end{array}$ \\
\hline $\begin{array}{l}\text { Baseline normal weight } \\
\left(\mathrm{BMI}<25 \mathrm{~kg} / \mathrm{m}^{2}\right)\end{array}$ & $51.57 \%$ & $19.66 \%$ & $26.88 \%$ & $40.00 \%$ & $13.20 \%$ \\
\hline Weight change (kg) & $1.94 \pm 4.10$ & $2.15 \pm 6.82$ & $-0.11 \pm 3.72$ & $2.33 \pm 4.27$ & $0.08 \pm 6.60$ \\
\hline Time change (yr) & $1.72 \pm 0.49$ & $1.96 \pm 0.39$ & $1.48 \pm 0.51$ & $1.99 \pm 0.24$ & $1.64 \pm 0.53$ \\
\hline Weight change rate $(\mathrm{kg} / \mathrm{yr})$ & $1.17 \pm 2.69$ & $0.98 \pm 3.40$ & $-0.03 \pm 2.79$ & $1.15 \pm 2.17$ & $0.002 \pm 4.27$ \\
\hline MVPA (min/day $10-\min$ bout) & $11.79 \pm 12.70$ & $10.17 \pm 10.14$ & $8.76 \pm 10.07$ & $11.00 \pm 10.33$ & $6.56 \pm 13.50$ \\
\hline MVPA (min/day 1-min bout) & $28.32 \pm 18.93$ & $22.31 \pm 15.41$ & $21.37 \pm 16.78$ & $24.44 \pm 14.62$ & $\begin{array}{c}15.77 \pm 19.3 \\
1\end{array}$ \\
\hline Light (min/day 10-min bout) & $165.07 \pm 72.60$ & $93.24 \pm 51.33$ & $112.39 \pm 60.48$ & $126.82 \pm 78.61$ & $\begin{array}{l}108.35 \pm 75 \\
74\end{array}$ \\
\hline
\end{tabular}




\begin{tabular}{|c|c|c|c|c|c|}
\hline Light (min/day 1-min bout) & $267.39 \pm 69.15$ & $200.04 \pm 57.36$ & $221.45 \pm 63.61$ & $229.54 \pm 73.61$ & $\begin{array}{c}223.29 \pm 77 \\
01\end{array}$ \\
\hline Sedentary (min/day 10-min bout) & $46.83 \pm 27.62$ & $61.02 \pm 37.70$ & $57.43 \pm 34.46$ & $52.56 \pm 33.95$ & $\begin{array}{c}52.36 \pm 35.6 \\
6\end{array}$ \\
\hline Sedentary (min/day 1 -min bout) & $222.69 \pm 41.70$ & $246.48 \pm 44.49$ & $243.93 \pm 45.42$ & $198.74 \pm 50.10$ & $\begin{array}{c}240.49 \pm 57 \\
39\end{array}$ \\
\hline Meets USA PA guidelines (Yes) & $38.12 \%$ & $24.79 \%$ & $28.49 \%$ & $29.30 \%$ & $14.72 \%$ \\
\hline
\end{tabular}




\section{Table 2 (on next page)}

Yearly weight change $(\mathrm{kg} / \mathrm{yr})$ for BMl status and meeting PA guidelines at baseline (MVPA $\geq 30 \mathrm{~min} /$ day) for men and women, by site (means \pm standard deviation). 


\begin{tabular}{|c|c|c|c|c|c|c|}
\hline & & Ghana & RSA & Jamaica & $\begin{array}{c}\text { Seychell } \\
\text { es }\end{array}$ & USA \\
\hline \multirow{4}{*}{ Men $(\mathrm{N}=888)$} & Normal weight $\left(\mathrm{BMI}<25 \mathrm{~kg} / \mathrm{m}^{2}\right)$ & $\mathrm{N}=129$ & $\mathrm{~N}=146$ & $\mathrm{~N}=121$ & $\mathrm{~N}=83$ & $\mathrm{~N}=49$ \\
\hline & & $0.58 \pm 2.09$ & $0.64 \pm 3.12$ & $0.14 \pm 2.26$ & $0.56 \pm 1.88$ & $\begin{array}{c}0.23 \pm 2.2 \\
2\end{array}$ \\
\hline & Overweight (BMI $\left.\geq 25-<30 \mathrm{~kg} / \mathrm{m}^{2}\right)$ & $\begin{array}{c}\mathbf{N}=\mathbf{2 4} \\
0.28 \pm 2.12\end{array}$ & $\begin{array}{c}\mathbf{N}=30 \\
-0.20 \pm 4.68\end{array}$ & $\begin{array}{c}\mathbf{N}=41 \\
0.44 \pm 3.67\end{array}$ & $\begin{array}{c}\mathbf{N}=73 \\
0.66 \pm 2.73\end{array}$ & $\begin{array}{c}\mathbf{N}=\mathbf{5 3} \\
- \\
0.27 \pm 2.9 \\
4\end{array}$ \\
\hline & Obese $\left(B M I \geq 25 \mathrm{~kg} / \mathrm{m}^{2}\right)$ & $\begin{array}{c}\mathbf{N}=\mathbf{3} \\
-2.06 \pm 4.67\end{array}$ & $\begin{array}{c}\mathbf{N}=\mathbf{7} \\
0.62 \pm 3.95\end{array}$ & $\begin{array}{c}\mathbf{N}=18 \\
0.21 \pm 6.99\end{array}$ & $\begin{array}{c}\mathrm{N}=42 \\
- \\
0.28 \pm 3.44\end{array}$ & $\begin{array}{c}\mathbf{N}=69 \\
- \\
0.16 \pm 6.3 \\
1\end{array}$ \\
\hline \multirow[t]{3}{*}{ Women $(\mathrm{N}=1,055)$} & Normal weight $\left(\mathrm{BMI}<25 \mathrm{~kg} / \mathrm{m}^{2}\right)$ & $\begin{array}{c}\mathbf{N}=115 \\
1.37 \pm 2.53\end{array}$ & $\begin{array}{c}\mathbf{N}=\mathbf{4 6} \\
1.00 \pm 3.30\end{array}$ & $\begin{array}{c}\mathbf{N}=\mathbf{5 0} \\
0.23 \pm 1.95\end{array}$ & $\begin{array}{c}\mathbf{N}=\mathbf{8 6} \\
1.29 \pm 1.88\end{array}$ & $\begin{array}{c}\mathbf{N}=26 \\
1.15 \pm 3.1 \\
4\end{array}$ \\
\hline & Overweight (BMI $\left.\geq 25-<30 \mathrm{~kg} / \mathrm{m}^{2}\right)$ & $\begin{array}{c}\mathbf{N}=\mathbf{7 5} \\
1.08 \pm 3.02\end{array}$ & $\begin{array}{c}\mathbf{N}=57 \\
1.35 \pm 3.41\end{array}$ & $\begin{array}{c}\mathbf{N}=41 \\
0.08 \pm 3.49\end{array}$ & $\begin{array}{c}\mathbf{N}=\mathbf{6 8} \\
1.30 \pm 2.06\end{array}$ & $\begin{array}{c}\mathbf{N}=41 \\
0.77 \pm 4.0 \\
8\end{array}$ \\
\hline & Obese $\left(\mathrm{BMI} \geq 25 \mathrm{~kg} / \mathrm{m}^{2}\right)$ & $\begin{array}{c}\mathbf{N}=\mathbf{3 3} \\
0.72 \pm 2.45\end{array}$ & $\begin{array}{c}\mathbf{N}=131 \\
0.81 \pm 3.44\end{array}$ & $\begin{array}{c}\mathbf{N}=95 \\
-0.21 \pm 2.84\end{array}$ & $\begin{array}{c}\mathbf{N}=\mathbf{6 1} \\
0.78 \pm 2.61\end{array}$ & $\begin{array}{c}\mathbf{N}=130 \\
- \\
0.47 \pm 4.4 \\
7\end{array}$ \\
\hline \multirow[t]{3}{*}{ Men $(\mathrm{N}=888)$} & Meets USA PA guidelines & $\begin{array}{c}\mathbf{N}=116 \\
0.54 \pm 2.21\end{array}$ & $\begin{array}{c}\mathbf{N}=140 \\
0.57 \pm 3.57\end{array}$ & $\begin{array}{c}\mathbf{N}=77 \\
0.59 \pm 4.35\end{array}$ & $\begin{array}{c}\mathbf{N}=110 \\
0.55 \pm 2.18\end{array}$ & $\begin{array}{c}\mathbf{N}=65 \\
0.25 \pm 5.0 \\
5\end{array}$ \\
\hline & Does not meet PA guidelines & $\mathrm{N}=40$ & $\mathrm{~N}=43$ & $\mathrm{~N}=103$ & $\mathrm{~N}=88$ & $\mathrm{~N}=106$ \\
\hline & & $0.30 \pm 2.02$ & $0.28 \pm 3.02$ & $-0.07 \pm 2.77$ & $0.25 \pm 3.06$ & $\begin{array}{c}- \\
0.29 \pm 4.0 \\
9\end{array}$ \\
\hline \multirow[t]{3}{*}{ Women $(\mathrm{N}=1,056)$} & Meets USA PA guidelines & $\mathrm{N}=85$ & $\mathrm{~N}=58$ & $\mathrm{~N}=53$ & $\mathrm{~N}=63$ & $\mathbf{N}=29$ \\
\hline & & $1.26 \pm 2.50$ & $1.75 \pm 3.09$ & $-0.03 \pm 3.13$ & $1.44 \pm 2.00$ & $\begin{array}{c}- \\
0.35 \pm 5.0 \\
5\end{array}$ \\
\hline & Does not meet PA guidelines & $\mathbf{N}=138$ & $\mathrm{~N}=176$ & $\mathrm{~N}=133$ & $\mathrm{~N}=152$ & $\mathbf{N}=169$ \\
\hline
\end{tabular}


1 Adjusted for age and time 


\section{Table 3(on next page)}

Overall weight loss/gain by site for men and women (means \pm standard deviation). 


\begin{tabular}{|c|c|c|c|c|c|c|}
\hline & & Ghana & RSA & Jamaica & Seychelles & USA \\
\hline \multirow{3}{*}{$\begin{array}{c}\text { Men } \\
(\mathbf{N}=874)\end{array}$} & Weight loss & $\mathrm{N}=51$ & $\mathrm{~N}=75$ & $\mathrm{~N}=74$ & $\mathrm{~N}=68$ & $\mathrm{~N}=75$ \\
\hline & & $-2.42 \pm 1.87$ & $-3.21 \pm 2.74$ & $-2.90 \pm 3.03$ & $-3.64 \pm 5.17$ & $-4.44 \pm 4.56$ \\
\hline & Weight gain & $\begin{array}{c}\mathbf{N}=\mathbf{7 2} \\
3.21 \pm 2.36\end{array}$ & $\begin{array}{c}\mathbf{N}=85 \\
4.49 \pm 3.50\end{array}$ & $\begin{array}{c}\mathbf{N}=71 \\
3.55 \pm 2.78\end{array}$ & $\begin{array}{c}\mathbf{N}=105 \\
3.88 \pm 3.43\end{array}$ & $\begin{array}{c}\mathbf{N}=79 \\
4.47 \pm 4.39\end{array}$ \\
\hline \multirow{2}{*}{$\begin{array}{l}\text { Women } \\
(N=1,048)\end{array}$} & Weight loss & $\begin{array}{c}\mathbf{N}=\mathbf{5 7} \\
-2.86 \pm 2.07\end{array}$ & $\begin{array}{c}\mathbf{N}=\mathbf{8 1} \\
-4.57 \pm 3.33\end{array}$ & $\begin{array}{c}\mathbf{N}=78 \\
-3.43 \pm 2.79\end{array}$ & $\begin{array}{c}\mathbf{N}=44 \\
-2.96 \pm 2.31\end{array}$ & $\begin{array}{c}\mathbf{N}=77 \\
-5.87 \pm 5.58\end{array}$ \\
\hline & Weight gain & $\begin{array}{c}\mathbf{N}=146 \\
4.04 \pm 3.17\end{array}$ & $\begin{array}{c}\mathbf{N}=137 \\
6.37 \pm 5.28\end{array}$ & $\begin{array}{c}\mathbf{N}=\mathbf{8 1} \\
3.06 \pm 1.85\end{array}$ & $\begin{array}{c}\mathbf{N}=148 \\
4.27 \pm 3.46\end{array}$ & $\begin{array}{c}\mathrm{N}=101 \\
4.65 \pm 3.66\end{array}$ \\
\hline
\end{tabular}




\section{Table 4(on next page)}

Correlations between weight change, weight gain and weight loss and baseline MVPA (1-min bouts) by site and gender. 


\begin{tabular}{|c|c|c|c|c|c|c|}
\hline \multirow[t]{2}{*}{ Table 4a } & \multicolumn{6}{|c|}{ Weight change velocity } \\
\hline & & Ghana & RSA & Jamaica & Seychelles & USA \\
\hline \multirow[t]{3}{*}{ Men } & Correlation & -0.044 & 0.039 & 0.056 & -0.017 & 0.046 \\
\hline & $p$-value & 0.58 & 0.60 & 0.46 & 0.81 & 0.55 \\
\hline & $\mathbf{N}$ & 156 & 183 & 180 & 198 & 171 \\
\hline \multirow[t]{3}{*}{ Women } & Correlation & -0.019 & 0.048 & 0.031 & 0.153 & -0.084 \\
\hline & p-value & 0.78 & 0.47 & 0.67 & 0.03 & 0.24 \\
\hline & $\mathbf{N}$ & 223 & 234 & 186 & 215 & 197 \\
\hline \multirow[t]{2}{*}{ Table 4b } & \multicolumn{6}{|c|}{ Weight gain (among participants who gained weight) } \\
\hline & & Ghana & RSA & Jamaica & Seychelles & USA \\
\hline \multirow[t]{3}{*}{ Men } & Correlation & -0.022 & -0.039 & 0.012 & -0.032 & 0.087 \\
\hline & p-value & 0.84 & 0.70 & 0.92 & 0.71 & 0.41 \\
\hline & $\mathbf{N}$ & 90 & 99 & 77 & 137 & 90 \\
\hline \multirow[t]{3}{*}{ Women } & Correlation & -0.080 & -0.021 & 0.004 & 0.091 & 0.064 \\
\hline & p-value & 0.32 & 0.79 & 0.97 & 0.24 & 0.50 \\
\hline & $\mathbf{N}$ & 158 & 157 & 93 & 167 & 115 \\
\hline \multirow[t]{2}{*}{ Table 4c } & \multicolumn{6}{|c|}{ Weight loss (among participants who lost weight) } \\
\hline & & Ghana & RSA & Jamaica & Seychelles & USA \\
\hline \multirow[t]{3}{*}{ Men } & Correlation & -0.015 & 0.092 & 0.055 & -0.021 & 0.264 \\
\hline & p-value & 0.91 & 0.39 & 0.63 & 0.85 & 0.02 \\
\hline & $\mathbf{N}$ & 59 & 90 & 79 & 89 & 82 \\
\hline \multirow[t]{3}{*}{ Women } & Correlation & 0.023 & 0.070 & -0.087 & 0.177 & -0.013 \\
\hline & $p$-value & 0.84 & 0.48 & 0.42 & 0.15 & 0.91 \\
\hline & $\mathbf{N}$ & 78 & 105 & 88 & 68 & 86 \\
\hline
\end{tabular}

1 Adjusted for age and time 


\section{Table 5 (on next page)}

Correlations between weight change, weight gain and weight loss and baseline sedentary time (1-min bouts) by site and gender. 


\begin{tabular}{|c|c|c|c|c|c|c|}
\hline \multirow[t]{2}{*}{ Table 5a } & \multicolumn{6}{|c|}{ Weight change } \\
\hline & & Ghana & RSA & Jamaica & Seychelles & USA \\
\hline \multirow[t]{3}{*}{ Men } & Correlation & 0.188 & 0.054 & -0.059 & -0.034 & -0.003 \\
\hline & $p$-value & 0.02 & 0.47 & 0.43 & 0.97 & 0.97 \\
\hline & $\mathbf{N}$ & 156 & 183 & 180 & 198 & 171 \\
\hline \multirow[t]{3}{*}{ Women } & Correlation & -0.140 & 0.025 & 0.008 & 0.014 & 0.044 \\
\hline & $p$-value & 0.04 & 0.70 & 0.91 & 0.84 & 0.54 \\
\hline & $\mathbf{N}$ & 223 & 234 & 186 & 215 & 197 \\
\hline \multirow[t]{2}{*}{ Table 5b } & \multicolumn{6}{|c|}{ Weight gain (among participants who gained weight) } \\
\hline & & Ghana & RSA & Jamaica & Seychelles & USA \\
\hline \multirow[t]{3}{*}{ Men } & Correlation & 0.011 & -0.001 & 0.001 & -0.014 & -0.043 \\
\hline & p-value & 0.92 & 0.99 & 0.188 & 0.87 & 0.69 \\
\hline & $\mathbf{N}$ & 90 & 99 & 99 & 137 & 90 \\
\hline \multirow[t]{3}{*}{ Women } & Correlation & -0.126 & 0.000 & -0.021 & 0.167 & 0.003 \\
\hline & p-value & 0.11 & 0.99 & 0.84 & 0.03 & 0.97 \\
\hline & $\mathbf{N}$ & 158 & 157 & 93 & 167 & 115 \\
\hline \multirow[t]{2}{*}{ Table 5c } & \multicolumn{6}{|c|}{ Weight loss (among participants who lost weight) } \\
\hline & & Ghana & RSA & Jamaica & Seychelles & USA \\
\hline \multirow[t]{3}{*}{ Men } & Correlation & 0.021 & 0.042 & -0.047 & -0.001 & 0.001 \\
\hline & p-value & 0.87 & 0.69 & 0.68 & 0.99 & 0.99 \\
\hline & $\mathbf{N}$ & 59 & 90 & 79 & 89 & 82 \\
\hline \multirow[t]{3}{*}{ Women } & Correlation & -0.005 & 0.214 & 0.009 & -0.031 & 0.339 \\
\hline & p-value & 0.9 & 0.03 & 0.93 & 0.80 & 0.001 \\
\hline & $\mathbf{N}$ & 78 & 105 & 88 & 68 & 86 \\
\hline
\end{tabular}

1 Adjusted for age and time 


\section{Table 6 (on next page)}

Parameter estimates from the mixed-effects models for weight, using baseline MVPA (model 1), light (model 2 ) and sedentary activity (model 3 ). 


\begin{tabular}{|c|c|c|c|c|c|c|c|c|c|}
\hline \multirow[b]{2}{*}{ Variable } & \multicolumn{3}{|c|}{ Model 1: MVPA (1-min bouts) } & \multicolumn{3}{|c|}{$\begin{array}{l}\text { Model 2: Light activity (1-min } \\
\text { bouts) }\end{array}$} & \multicolumn{3}{|c|}{$\begin{array}{l}\text { Model 3: Sedentary activity (1 -min } \\
\text { bouts) }\end{array}$} \\
\hline & $\begin{array}{c}\text { Estimat } \\
\mathrm{e}\end{array}$ & $95 \% \mathrm{Cl}$ & p-value & $\begin{array}{c}\text { Estimat } \\
\mathrm{e}\end{array}$ & $95 \% \mathrm{Cl}$ & p-value & Estimate & $95 \% \mathrm{Cl}$ & p-value \\
\hline Intercept & 4.288 & $(2.688-5.887)$ & $<0.001$ & 4.448 & $(2.56,6.33)$ & $<0.001$ & 3.995 & $(1.766,6.224)$ & $<0.001$ \\
\hline baseline weight (kg) & 0.986 & $(0.976-0.995)$ & $<0.001$ & 0.98 & $(0.975,0.993)$ & $<0.001$ & 0.985 & $(0.976,0.994)$ & $<0.001$ \\
\hline Age $(y)$ & -0.059 & $(-0.088,-0.0316)$ & $<0.001$ & -0.062 & $(-0.090,-0.034)$ & $<0.001$ & -0.06 & $\begin{array}{c}(-0.089,- \\
0.032) \\
\end{array}$ & $<0.001$ \\
\hline Men & -0.45 & $(-0.821,-0.078)$ & 0.02 & -0.653 & $(-0.996,-0.301)$ & $<0.001$ & -0.665 & $\begin{array}{c}(-1.009,- \\
0.320)\end{array}$ & $<0.001$ \\
\hline Site & & & 0.29 & & & 0.34 & & & 0.28 \\
\hline Ghana & -0.569 & $(-1.75,0.611)$ & 0.34 & -0.528 & $(-1.705,0.649)$ & 0.38 & -0.447 & $(-1.621,0.728)$ & 0.46 \\
\hline RSA & -0.924 & $(-2.02,0.168)$ & 0.1 & -0.874 & $(-1.959,0.211)$ & 0.11 & -0.877 & $(-1.950,0.196)$ & 0.11 \\
\hline Jamaica & -0.184 & $(-1.546,1.179)$ & 0.79 & -0.173 & $(-1.531,1.184)$ & 0.8 & -0.199 & $(-1.557,1.160)$ & 0.77 \\
\hline Seychelles & -0.008 & $(-1.100,1.085)$ & 0.99 & -0.019 & $(-1.104,1.067)$ & 0.97 & 0.087 & $(-1.032,1.207)$ & 0.88 \\
\hline $\begin{array}{l}\text { Activity estimate (1- } \\
\text { min bout) }\end{array}$ & 0.0004 & $(-0.013,0.013)$ & 0.95 & 0.0003 & $(-0.004,0.005)$ & 0.88 & 0.002 & $(-0.005,0.008)$ & 0.61 \\
\hline Follow-up time (mo) & -0.201 & $(-0.905,0.502)$ & 0.57 & 0.176 & $(-0.855,1.207)$ & 0.74 & 0.036 & $(-1.376,1.449)$ & 0.96 \\
\hline Follow-up time*site & & & 0.06 & & & 0.052 & & & 0.05 \\
\hline Ghana & 0.644 & $(-0.247,1.535)$ & 0.16 & 0.632 & $(-0.253,1.517)$ & 0.16 & 0.586 & $(-0.296,1.469)$ & 0.19 \\
\hline RSA & 0.961 & $(0.124,1.798)$ & 0.02 & 0.94 & $(0.112,1.768)$ & 0.03 & 0.966 & $(0.145,1.787)$ & 0.02 \\
\hline Jamaica & -0.329 & $(-1.42,0.760)$ & 0.55 & -0.35 & $(-1.435,0.736)$ & 0.53 & -0.337 & $(-1.424,0.749)$ & 0.54 \\
\hline Seychelles & 0.54 & $(-0.281,1.361)$ & 0.2 & 0.576 & $(-0.238,1.390)$ & 0.17 & 0.556 & $(-0.286,1.398)$ & 0.20 \\
\hline $\begin{array}{l}\text { MVPA*follow-up } \\
\text { time }\end{array}$ & 0.001 & $(-0.009,0.011)$ & 0.83 & -0.001 & $(-0.005,0.002)$ & 0.46 & -0.0009 & $(-0.006,0.004)$ & 0.77 \\
\hline
\end{tabular}
1 
Figure 1

The correlation coefficient (adjusted for age and follow up time) between weight change and MVPA (1-min bouts) for men is 0.03459 ( $n=869, p=0.3091)$.
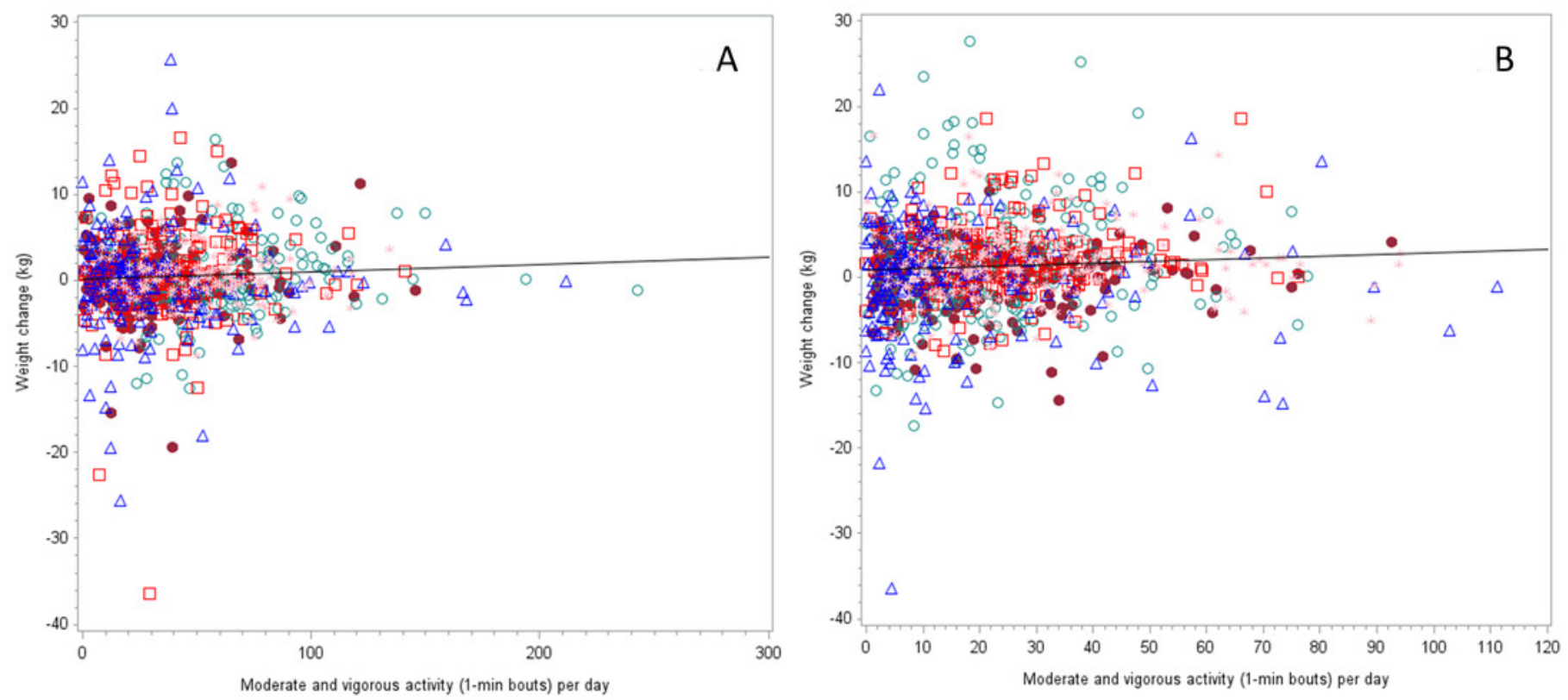

- $\mathrm{GH} \circ \mathrm{RSA} \square$ JA $\triangle$ SEY * USA 
Figure 2

The correlation coefficient (adjusted for age and follow up time) between weight change and MVPA (1-min bouts) for women is 0.05997 ( $n=1027, p=0.0549$ ).
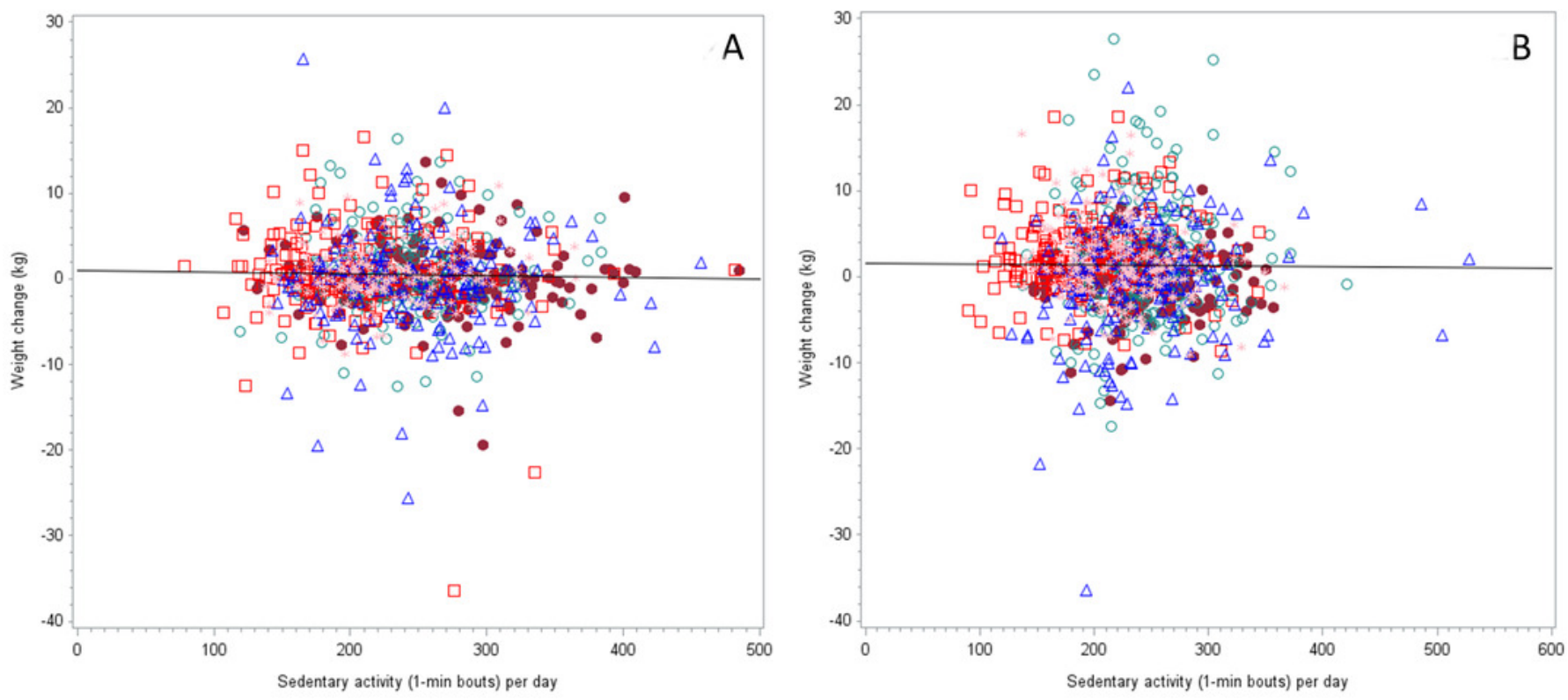

- $\mathrm{GH} \circ \mathrm{RSA}$ 口 JA $\triangle \mathrm{SEY} *$ USA 